\title{
Influence of Farmers' Socio-economic Characteristics in Selection of Climate Change Adaptive Strategies
}

\author{
Mpho Tshikororo ${ }^{1}$, Phineas Khazamula Chauke ${ }^{1} \&$ Jethro Zuwarimwe ${ }^{2}$ \\ ${ }^{1}$ School of Agriculture, Department of Agricultural Economics and Agribusiness, University of Venda, Republic \\ of South Africa \\ ${ }^{2}$ School of Agriculture, Institute of Rural Development, University of Venda, Republic of South Africa \\ Correspondence: Mpho Tshikororo, School of Agriculture, Department of Agricultural Economics and \\ Agribusiness, University of Venda, Private Bag X 5050, Thohoyandou 0950; Limpopo, Republic of South Africa. \\ Tel: 27-159-628-712. E-mail: mpho.tshikororo@univen.ac.za
}

Received: October 14, 2020

Accepted: January 28, $2021 \quad$ Online Published: February 15, 2021

doi:10.5539/jas.v13n3p135

URL: https://doi.org/10.5539/jas.v13n3p135

\begin{abstract}
Climate change is a global phenomenon that has been of great concern and its tackle is of outmost importance for food security and poverty alleviation among other things. This paper assessed the decisions informing selection of climate change adaptive strategies in Limpopo Province based on farmers' socio-economic characteristics. Data was collected from all five districts of Limpopo province namely; Sekhukhune, Waterberg, Mopani, Capricorn and Vhembe. A questionnaire administered in a face to face interviews was used to collect data on various climate change adaptive strategies used by emerging farmers in Limpopo province of South Africa. The most identified strategies identified were crop diversification, substitution of crops, calendar redefinition, changing crop rotation patterns and fertilizer application. Results from the multinomial logistic regression model employed indicated that farmers' socio-economic characteristics such as gender, age group, formal education, farming experience and household size significantly influenced farmers' selection of climate change adaptive strategies. As a conclusion, farmers' socio-economic characteristics are the major influencing factors determining selection of specific adaptive strategies. The study recommended that to enhance adaptive strategy uptake there should be a careful consideration of socio-economic characteristics that suits a need of specific farmers as farmers' adaptation to climate change varies individually.
\end{abstract}

Keywords: climate change, adaptive strategies, emerging farmers, socio-economic characteristics, selection

\section{Introduction}

Climate change and climate variability have been found to be crucial elements affecting agriculture performance across the world (FAO, 2007). Agricultural productivity in Africa has considerably been negatively affected by climate change (Ziervogel et al., 2006) to an extent that the continent's population is being threatened by food and nutrition insecurity. It is within that context that research is being encouraged to understand climate change adaptive strategies that could be used to mitigate impacts of climate change on agriculture (Jha \& Gupta, 2016). It is important to adapt agricultural production to climate change as it has been found that agricultural activities also contribute to climate change. In 2010, agricultural activities accounted for about $10-12 \%$ of human-generated greenhouse gas emissions (Pye-Smith, 2011). Research has shown that climate change results in high level of food insecurity around the globe (Pereira et al., 2014). This is more pronounced in developing countries, especially for crops and livestock enterprises run by emerging farmers whose adaptive capacity is limited (Madzwamuse, 2010). Adaptive strategies to climate change refer to an adjustment process that occurs through natural and human systems in response to climatic stimuli which might be harmful or beneficial to the system (Deressa et al., 2008; IPCC, 2001). From the literature, the study drew more focus on common adaptive strategies that are used in developing countries namely; crop diversification, substitution of crops, resilient crop varieties, calendar redefinition, fertilizer application and changing crop rotation pattern. While there are plentiful explanations of various adaptive strategies, the study has identified crop diversification as the addition of new crops or cropping systems to agricultural production on a farm considering the different returns from value added crops with complementary marketing opportunities (Khanam et al., 2018). Resilient crop varieties is a strategy of using types of crops that are resistant to climate change. Substitution of crops involves a practice of 
substituting one crop with another one, and fertilizer application refers to a strategy where farmers apply fertilizer or chemicals on their crops, whereas calendar redefinition refers to changing planting date to facilitate adaptation by way of planning when to plant such crops (Yéo et al., 2016). Interaction between the characteristics of the farm household and farm strategy clearly determine differential adoption levels (Hammond et al., 2016). Within that context, the design of adaptive strategies should consider specific farmers' context and different needs. Evidence shows that adaptation process is best effective when it is carried out at farm level (Arunrat et al., 2017). Tambo et al. (2013) noted that adaptive strategies should be locally designed and implemented to be successful.

Farmers' socio-economic characteristics, the subject of this paper, are essential elements in the selection of adaptive strategies to climate change (Mugi-Ngenga et al., 2016). For an effective uptake of climate change adaptive strategies by farmers, socio-economic characteristics should be significantly considered particularly at farm level (Mulinde et al., 2019). Regardless of available adaptive strategies to farmers, their socio-economic characteristics such as education, household income and household size were identified as key determinants to adaptation (Ndamani \& Watanabe, 2016). Similarly, a study by Gichangi and Gatheru (2018) ended up concluding that adaptive strategies in some cases have mainly relied on gender, age, education and wealth status of farmers. Within that context, the design of adaptive strategies should consider specific farmers' context and different needs. The aim of this paper was therefore, to assess the impact of socio economic factors of emerging farmers in Limpopo province of South Africa towards the selection of climate change adaptive strategies.

\section{Material and Methods}

The study was carried out in Limpopo province, ranked the 5th largest of the nine provinces of South Africa. Limpopo is in the northernmost part of the country and covers about $125,754 \mathrm{~km}^{2}$; with the population estimated to be about 5,726,800 people (Statistics South Africa, 2015). Limpopo province shares international borders with Botswana, Zimbabwe and Mozambique (LTA, 2014). Limpopo province is divided into five municipal districts; Capricorn, Mopani, Sekhukhune, Vhembe and Waterberg. The province has an abundance of agricultural resources. It is therefore the country's prime agricultural regions well-known for livestock, fruits, vegetables, cereals and tea production (LTA, 2014).

A two-stage cluster sampling technique was used to select 206 out of 550 farmers. In this sampling technique, the researcher picks groups or clusters, and then from each cluster, the researcher selects the individual subjects and further employs a systematic random sampling as it allows the researcher to add a degree of system or process into the random selection of subjects (Eplorable.com, 2009). Farmers from all five districts of the province were proportionally selected for inclusion using the clustered random selection technique. Farmers were clustered firstly into five districts and further into local municipalities where they were systematically random sampled from each local municipality. Questionnaires consisted of a logical flow of closed and open-ended questions were used to collect data on issues related to climate change adaptation, adaptive strategies and farmers' socio-economic characteristics. Data was collected through face to face interviews with the farmers; 206 questionnaires were administered during face to face interview sessions.

\section{Empirical Model}

Table 1 shows explanatory variables for the empirical multinomial logit model on farmer's selection of climate change adaptive strategies. The Multinomial Logit (MNL) model was used to analyze the influence of socio-economic characteristics on selection of adaptive strategies in the Limpopo Province. This method was considered due to its ability to produce robust results on ordinal and nominal scale type of data. The model was also used elsewhere and produced robust results in similar studies to analyze selection of adaptive strategies (Pundo \& Fraser, 2006; Hassan \& Nhemachena, 2008). Multinomial logit model (used to analyze more than two discrete choices) is the extension of the logit model. The advantage of the MNL is that it permits the analysis of assessments across more than two categories, allowing the determination of selection probabilities for different categories (Wooldridge, 2002). The probability that a farmer chooses one type of adaptive strategy is bounded between 0 and 1.

The model requires that the dependent variable be measured at the nominal level, and the independent variables are assumed to be either continuous or ordinal levels. However, the ordinal variable should be treated as being either continuous or categorical. Independent and dependent variables should have mutually exclusive and exhaustive categories that are not highly correlated with each other (no multicollinearity). Therefore, it is crucial to assess the relationship between independent variables before employing multinomial logit model.

To describe the MNL model adopted, let y (adaptive strategies) denote a random variable taking on the values $[0,1$, $2, \ldots \mathrm{J}]$ for $\mathrm{J}$, a positive integer, and let $\mathrm{x}$ denote a set of conditioning variables. In this case, $\mathrm{y}$ denotes adaptive 
strategies and $\mathrm{x}$ denotes different socio-economic characteristics (Gender, Age group, Marital status, Formal education, Agricultural education, Household size, Farming experience, Occupation, Off-farm income, Farm size, and Monthly farm income). The question is cetirus paribus, what are the changes in the elements of $\mathrm{x}$ affecting the selection of adaptive strategies probabilities $P(y=j / x), j=1,2, \ldots$. . Since the probabilities must sum to unit, $P(y=$ $\mathrm{j} / \mathrm{x}$ ) is determined once we know the probabilities for $\mathrm{j}=2,3, \ldots \mathrm{J}$.

Assuming $\mathrm{x}$ to be a $1 \times \mathrm{K}$ vector with first element being unit, then the MNL model has response probabilities given as follows:

$$
P(y=j / x)=\frac{\exp (x \beta j)}{\left[1+\sum_{h-1}^{j} \exp (x \beta h), j=1,2, \ldots J\right]}
$$

Where, $\beta \mathrm{j}$ is $\mathrm{K} \times 1, \mathrm{j}=1,2, \ldots \mathrm{J}$.

In this study, the possible adaptive strategies considered are six which are: Unbiased and consistent parameter estimates of the MNL model in Equation (1) require the assumption of independence of irrelevant alternatives (IIA) to hold. In particular, the IIA assumption requires that the probability of selecting a certain adaptive strategy by a given socio-economic character needs to be independent from the probability of choosing another adaptive strategy. The premise of the IIA assumption is the independent and homoscedastic disturbance terms of the basic model in Equation (1). The parameter estimates of the MNL model provide only the direction of the effect of the independent variables on the dependent (response) variable, but the estimates do not represent either the actual magnitude of change. Differentiating Equation (1) with respect to the explanatory variables provides marginal effects of the explanatory variables given as:

$$
\frac{\partial P \mathrm{j}}{\partial \mathrm{xk}}=\operatorname{Pj}\left(\beta \mathrm{jk}-\sum_{\mathrm{j}=1}^{\mathrm{j}-1} \operatorname{Pj} \beta \mathrm{jk}\right)
$$

The marginal effects are functions of the probability itself and measure the expected change in probability of a particular adaptive strategy selected with respect to a unit change in the independent variable from the mean (Greene, 2003).

Table 1. Description of explanatory variables used in the regression model

\begin{tabular}{llll}
\hline Variable Name description & Type of measure & Expected sign \\
\hline X1 & Marital Status & Dummy; $0=$ married, $1=$ not married & $-/+$ \\
X2 & Gender & Dummy; $0=$ female, $1=$ male & $-/+$ \\
X3 & Educational level & $0=$ no qualification, $1=$ primary, $2=$ secondary, $3=$ tertiary, $4=$ others & + \\
X4 & Agricultural education & Dummy; $0=$ no agricultural education, $1=$ has agricultural education & + \\
X5 & Age group & $0=$ under $21,1=21-39,2=40-59,3=60$ and older & $-/+$ \\
X6 & Farming experience & $0=$ less than a year, $1=1-5,2=6-10,3=$ more than 10 years & + \\
X7 & Occupation & $0=$ farming, $1=$ unemployed, $2=$ employed, $3=$ pensioner, $4=$ self-employed & - \\
X8 & Off-farm income & $0=$ employed, $1=$ pension, $2=$ remittances, $3=$ others & - \\
X9 & Farm size & $0=1-5$ ha, $1=6-10$ ha, $2=11-15$ ha, $3=$ more than 15 ha & + \\
X10 & Household size & $0=1-5,1=6-10,2=11-15,3=$ more than 15 & + \\
\hline
\end{tabular}

Note. Dependent variable $=$ adaptive strategies (Resilient crop varieties $=0$; Crop diversification $=1$; Substitution of crops $=2$; Calendar redefinition $=3$; Fertilizer application $=4$; Crop rotation $=5$ ).

\section{Model Results and Discussion}

Pearson correlation coefficient was performed to determine variables that could be useful for analysis to avoid using variables that are highly correlated. Pearson correlation coefficient was useful in measuring and quantifying the strength of the association between socio-economic characteristics before logistic analysis (Norusis, 1988). The analysis was useful in determining if ever multicollinearity existed in the dataset which could undesirably impact the performance of the model. A relationship that scores a value of 1 indicates a strongest positive relationship between variables, -1 also represent a strongest negative association between variables though such association. 0.5 symbolizes a moderate relationship between variables. There was no multicollinearity that existed among variables as shown in Table 2, hence all variables were included in analysis shown in Table 3. 
Table 2. Pair wise correlation matrix of explanatory variables

\begin{tabular}{|c|c|c|c|c|c|c|c|c|c|c|}
\hline & GEN & AGE & MS & FEDU & AGRICEDU & HSIZE & FE & OCC & OFI & MI \\
\hline GEN & 1 & & & & & & & & & \\
\hline AGE & $-.186^{* *}$ & 1 & & & & & & & & \\
\hline MS & -.093 & $-.285^{* *}$ & 1 & & & & & & & \\
\hline FEDU & $.204^{* *}$ & $-.398^{* *}$ & .094 & 1 & & & & & & \\
\hline AGRICEDU & .123 & .078 & -.013 & -.132 & 1 & & & & & \\
\hline HSIZE & $-.165^{*}$ & $.198^{* *}$ & -.091 & $-.147^{*}$ & .005 & 1 & & & & \\
\hline $\mathrm{FE}$ & $-.258^{* *}$ & $.434^{* *}$ & $-.170^{*}$ & $-.288^{* *}$ & .111 & $.202^{* *}$ & 1 & & & \\
\hline OCC & -.055 & $.149^{*}$ & -.007 & -.043 & .052 & -.025 & .076 & 1 & & \\
\hline OFI & $.217^{* *}$ & $-.496^{* *}$ & .086 & $.312^{* *}$ & .012 & -.024 & $-.294^{* *}$ & $-.345^{* *}$ & 1 & \\
\hline MI & .027 & .062 & $-.150^{*}$ & .135 & $-.198^{* *}$ & .067 & -.006 & -.044 & .025 & 1 \\
\hline
\end{tabular}

Note. $* * *, * *, *$ Significant at $1 \%, 5 \%$, and $10 \%$ probability level, respectively.

The estimation of the multinomial logit model for this study was assumed by standardizing one category, which is normally referred to as the "base category" and in this analysis, the base category is (Resilient crop varieties). The model established and explained the relationship between selection of adaptive strategies and farmers' socio-economic characteristics variables. The dependent variable was adaptive strategies with five strategies (crop diversification, substitution of crops, calendar redefinition, increase in fertilizer application and changing crop rotation patterns). The reference group for the study was resilient crop varieties.

Table 3. Parameter estimates of the multinomial logit climate change adaptation model

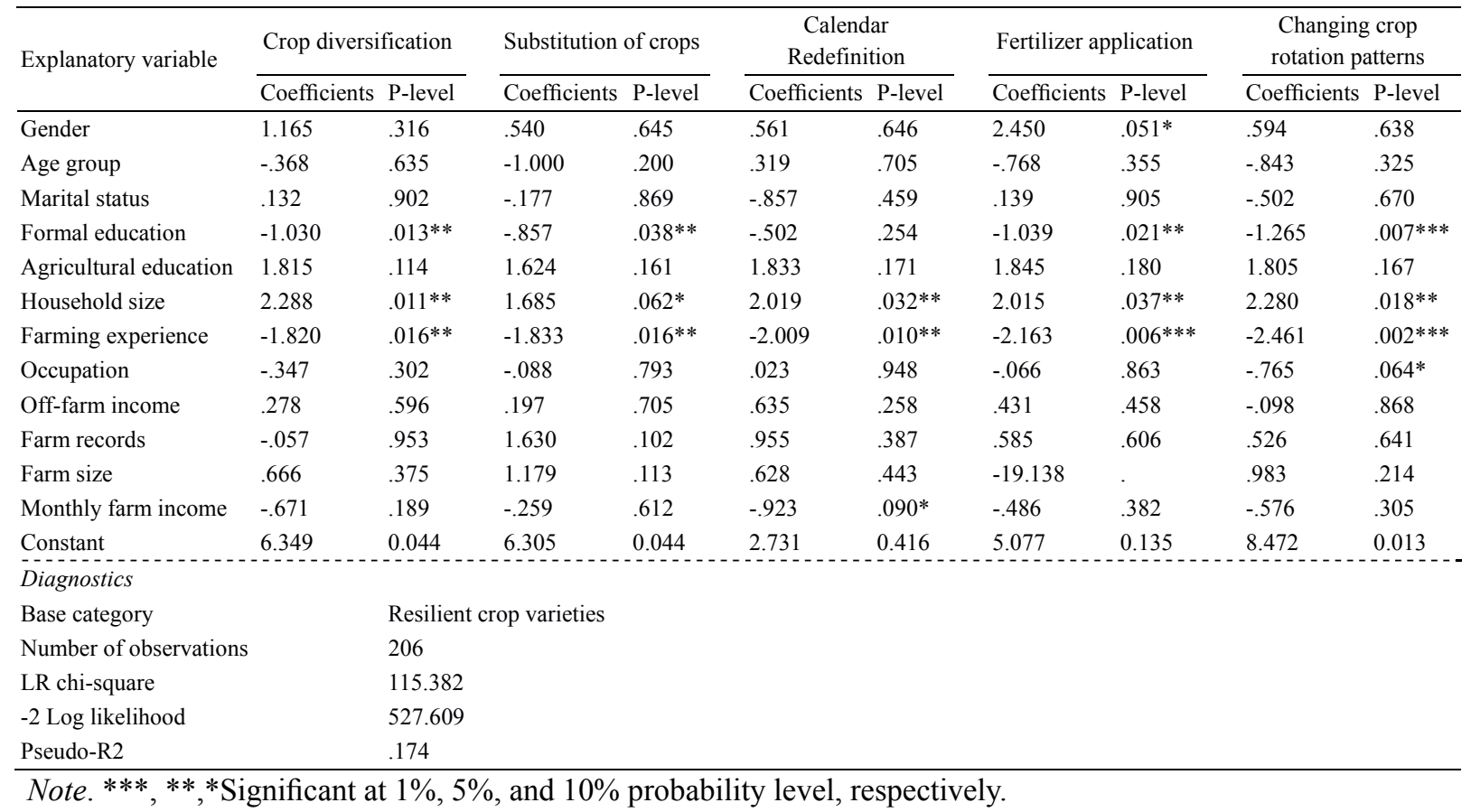

\subsection{Farmers' Gender}

The results indicate that farmers' gender significantly increases probabilities of adapting to climate change. Results in Table 3 shows that when male farmers dominate, selection of fertilizer application as an ideal strategy to adapt to climate change increases. This implies that male farmers are more likely to apply fertilizers as a strategy to survive the impacts of climate change more than female farmers. Furthermore, this results shows that farmers' gender has a significant influence towards application of fertilizer as a strategy to cope with the impacts of climate change. This result confirms the outcome of a study conducted by Jin et al. (2015) which concluded that male farmers are more willing to adapt to climate change more than their counterparts due to workforce requirement that is inherent in other adaptive strategies. 


\subsection{Formal Education}

Formal education was found to be significantly associated with selection of most climate adaptive strategies (crop diversification, substitution of crops, fertilizer application and changing crop rotation patterns). An increase in the years of schooling leads to a gradual decrease of selecting crop diversification strategy whilst an increase in years of schooling also decreases selection of substitution of crops among farmers. Farmers who spend another year schooling progressively decrease selection of application of fertilizer and changing of crop rotation patterns strategies respectively. As reflected in Table 1 above this outcome was unexpected, as acquiring formal education was perceived to positively influence selection of various climate change adaptive strategies. The findings of this study are contrary to that of Recha et al. (2015) who revealed that the number of years that farmers spent at school plays a significant and positive role in selecting adaptive strategies. Consequently, as observed by Abdul-Razak and Kruse (2018) formal education opens various opportunities for farmers to earn a living including off-farm income generation as a cushion against the negative impact of climate change and this is the reason why formal education may have a negative impact towards adoption of various strategies.

\subsection{Household Size}

Farmers' household size has a significant and positive influence on selection of all climate change adaptive strategies. The findings of this study indicate that an increase in household size positively influence selection of all climate change adaptive strategies. The findings of this study propose that the availability of labour force through household members increases farmers' willingness to adapt to climate change using various adaptive strategies. This is consistent with the findings of Awazi and Tchamba (2018) who revealed that farming families with larger households are more willing to adopt various adaptive strategies than smaller household families. Larger household size enhances farming families' willingness to adapt to climate change.

\subsection{Farming Experience}

Farming experience was found to have a statistical significant but negative association with selection of all climate change adaptive strategies. This implies that each year a farmer gains more farming experience, selection of climate change adaptive strategies stands a chance of being less selected. It further implies that each time a farmer add a year of farming it lessens their willingness to adapt various climate change adaptive strategies. Farmers who have been exposed to impacts of climate change are more willing to adapt to climate change more than their counterparts. The findings of this study showing that an increase in farming experience leads to a decrease in selection of specific adaptive strategies is supported by the findings of Shikuku et al. (2017) who indicated that more farming experience among farmers negatively affect farmers' decision to select various adaptive strategies. Farmers with a vast farming experience are in a better position to know adaptive strategies that are effective for them as noted by Niles et al. (2016) who stated that farmers who might have an experience of adapting adaptive strategies may not be willing to continue adapting such strategies in the future. Furthermore, the findings are also consistent with that of Jin et al. (2015) who revealed that farming experience also has a negative impact for both male and female farmers towards adoption of new adaptive strategies.

\subsection{On-Farm Monthly Income}

On-farm monthly income that farmers generate has a significant but negative influence towards selection of calendar redefinition strategy to mitigate the impact of climate change. This implies that calendar redefinition strategy may not be yielding the most desirable level of income and farmers may find it less effective which leads to less selection of the strategy among farmers. The findings of this study contrast with that of Burnham and Ma (2017) who revealed that farmers who earns higher on-farm income are more willing to make use of various adaptive strategies including adoption of calendar redefinition.

\subsection{Off-Farm Occupation}

Securing off-farm occupation was only found to significantly influence adoption of changing crop rotation patterns as an ideal strategy to combat impact of climate change. Securing off-farm occupation has a significant but negative influence on the selection of changing crop rotation patterns strategy. The implication of the results is that when farmers acquires off-farm occupation it weakens their drive to adapt to climate change through changing crop rotation strategy. This was also expected as depicted on Table 1 that securing off-farm income negatively impact adoption of adaptive strategies among farmers. The findings of this study are closely related to the findings of Mugi-Ngenga et al. (2016) who attested that farmers with stable off farming income have a low level of adaptation compared to those who are sorely focused on farming. 


\section{Conclusions and Policy Implications}

This paper assessed the influence of farmers' socio-economic characteristics in the selection of climate change adaptive strategies. The results of this study showed that some of farmers' socio-economic characteristics of farmers significantly influence selection of adaptive strategies. Farmers' household size has a positive influence on selection of crop diversification, substitution of crops, calendar redefinition, fertilizer application and changing crop rotation patterns. This study therefore recommends that with sufficient resources such as labor force and climate change information, farmers should be trained to adapt different adaptive strategies within their farming unit. The study therefore recommends that training should be prioritized to farmers who are less educated and those who are illiterate as they may not have many off-farm activities to invest in. Gaining more farming experience was found to have a significant but negative association with the selection of all adaptive strategies hence the study recommends effective adaptation training for experienced farmers and less experienced farmers should be conducted separately to cater for their specific needs. The findings revealed that off-farm occupation has a significant but negative influence on the selection of changing crop rotation pattern. It is therefore recommended that for changing crop rotation pattern, assistance to adapt to climate change should be prioritized for farmers who do not have off-farm occupation as it distract farmers from adapting to climate change. The study further recommends that there should be trainings for young and elderly farmers separately based on their specific needs as well as identifying specific strategies that targets experienced farmers and those with less farming experience. The study also recommends that for every climate change adaption initiatives, farmers should be involved and be assisted through various curricula that intends to build farmers' resilience to climate change based on their specific socio-economic characteristics. Every adaptive strategy identified, there should be a careful consideration of specific socio-economic characteristics that suits a certain need for farmers since adaptation can be best measured at a farm level.

\section{Acknowledgements}

Authors highly appreciate financial assistance received from the University of Venda Research and Publication Committee and National Research Foundation. Furthermore, authors would particularly like to thank all the 206 participants for their engagement in the study.

\section{References}

Abdul-Razak, M., \& Kruse, S. (2017). The adaptive capacity of smallholder farmers to climate change in the Northern Region of Ghana. Climate Risk Management, 17, 104-122. https://doi.org/10.1016/j.crm.2017. 06.001

Arunrat, N., Wang, C., Pumijumnong, N., Sereenonchai, S., \& Cai, W. (2017). Farmers' intention and decision to adapt to climate change: A case study in the Yom and Nan basins, Phichit province of Thailand. Journal of Cleaner Production, 143, 672-685. https://doi.org/10.1016/j.jclepro.2016.12.058

Awazi, N. P., \& Tchamba, M. N. (2018). Determinants of small-scale farmers' adaptation decision to climate variability and change in the North-West region of Cameroon. African Journal of Agricultural Research, 13(12), 534-543. https://doi.org/10.5897/AJAR2018.12971

Burnham, M., \& Ma, Z. (2017). Climate change adaptation: Factors influencing Chinese smallholder farmers' perceived self-efficacy and adaptation intent. Regional Environmental Change, 17(1), 171-186. https://doi.org/10.1007/s10113-016-0975-6

Deressa, T. T., Hassan, R. M., Alemu, T., Yesuf, M., \& Ringler, C. (2008). Analysing the determinants of farmers' choice of adaptation methods and perceptions of climate change in the Nile Basin of Ethiopia (IFPRI Discussion Paper 00798). If women hold up half the sky, how much of the world's food do they produce? (ESA Working Paper No. 1104). Rome: FAO.

Explorable. (2009). Retrieved February 4, 2017, from https://explorable.com

FAO. (2007). Adaptation to climate change in agriculture, forestry and fisheries: Perspective, framework and priorities. FAO, Rome.

Gichangi, E. M., \&d Gatheru, M. (2018). Farmers' awareness and perception of climate change and the various adaptation measures they employ in the semiarid eastern Kenya. Climate Change, 4(14), 112-122.

Greene, W. H. (2003). Econometric analysis. Pearson Education India.

Hammond, J., Fraval, S., van Etten, J., Suchini, J. G., Mercado, L., Pagella, T., ... Valbuena, D. (2016). The Rural Household Multi-Indicator Survey (RHoMIS) for rapid characterization of households to inform 
climate smart agriculture interventions: Description and applications in East Africa and Central America. Agricultural Systems, 151, 225-233. https://doi.org/10.1016/j.agsy.2016.05.003

Hassan, R., \& Nhemachena, C. (2008). Determinants of African farmers' strategies for adapting to climate change: Multinomial choice analysis. African Journal of Agricultural and Resource Economics, 2(1).

IPCC. (2011). Managing the risks of extreme events and disasters to advance climate change adaptation: A special report on working group I and working group II of the intergovernmental panel on climate change. Retrieved August 2, 2016, from http://www.ipcc.ch/ipccreports/ar4-syr.htm

Jha, C. K., \& Gupta, V. (2016). Climate Change Adaptation in Indian Agriculture Assessing Farmers' Perception and Adaptive Choices. Climate Change Adaptation, Resilience and Hazards (pp. 275-288). Springer International Publishing. https://doi.org/10.1007/978-3-319-39880-8_17

Jin, J., Wang, X., \& Gao, Y. (2015). Gender differences in farmers' responses to climate change adaptation in Yongqiao District, China. Science of the Total Environment, 538, 942-948. https://doi.org/10.1016/ j.scitotenv.2015.07.027

Khanam, R., Bhaduri, D., \& Nayak, A. K. (2018). Crop diversification: an important way-out for doubling farmers' income. Indian Farming, 68(01), 31-32.

Limpopo Travel Agency. (2014). Retrieved February 4, 2017, from http://www.golimpopo.com

Madzwamuse, M., (2010). Climate governance in Africa: Adaptation strategies and institutions. Retrieved July 2, 2016, from http://www.za.boell.org

Mugi-Ngenga, E. W., Mucheru-Muna, M. W., Mugwe, J. N., Ngetich, F. K., Mairura, F. S., \& Mugendi, D. N. (2016). Household's socio-economic factors influencing the level of adaptation to climate variability in the dry zones of Eastern Kenya. Journal of Rural Studies, 43, 49-60. https://doi.org/10.1016/j.jrurstud. 2015.11.004

Mulinde, C., Majaliwa, J. G. M., Twinomuhangi, R., Mfitumukiza, D., Komutunga, E., Ampaire, E., ... Jassogne, L. (2019). Perceived climate risks and adaptation drivers in diverse coffee landscapes of Uganda. NJAS-Wageningen. Journal of Life Sciences, 88, 31-44. https://doi.org/10.1016/j.njas.2018.12.002

Ndamani, F., \& Watanabe, T. (2016). Determinants of farmers' adaptation to climate change: A micro level analysis in Ghana. Scientia Agricola, 73(3), 201-208. https://doi.org/10.1590/0103-9016-2015-0163

Niles, M. T., Brown, M., \& Dynes, R., (2016). Farmer's intended and actual adoption of climate change mitigation and adaptation strategies. Climatic Change, 135(2), 277-295. https://doi.org/10.1007/s10584015-1558-0

Norusis, M. J. (1988). SPSS/PC+ V2.0 Base Manual (pp. 99-103).

Pundo, M. O., \& Fraser, G. C. (2006). Multinomial logit analysis of household cooking fuel choice in rural Kenya: The case of Kisumu district. Agrekon, 45(1), 24-37. https://doi.org/10.1080/03031853.2006. 9523731

Pye-Smith, C., (2011). Farming's climate-smart future: Placing agriculture at the heart of climate-change policy.

Recha, C. W., Mukopi, M. N., \& Otieno, J. O. (2015). Socio-economic determinants of adoption of rainwater harvesting and conservation techniques in semi-arid Tharaka sub-county, Kenya. Land Degradation \& Development, 26(7), 765-773. https://doi.org/10.1002/ldr.2326

Shikuku, K. M., Winowiecki, L., Twyman, J., Eitzinger, A., Perez, J. G., Mwongera, C., \& Läderach, P. (2017). Smallholder farmers' attitudes and determinants of adaptation to climate risks in East Africa. Climate Risk Management, 16, 234-245. https://doi.org/10.1016/j.crm.2017.03.001

STATSSA (Statistics South Africa). (2015). First quarter publication. Retrieved on February 6, 2017, from https://www.statssa.gov.za

Tambo, J. A., \& Abdoulaye, T. (2013). Smallholder farmers' perceptions of and adaptations to climate change in the Nigerian savanna. Regional Environmental Change, 13(2), 375-388. https://doi.org/10.1007/s10113012-0351-0

Wooldridge, J. M. (2010). Econometric analysis of cross section and panel data. MIT Press. 
Yéo, W. E., Goula, B. T. A., Diekkrüger, B., \& Afouda, A. (2016). Vulnerability and adaptation to climate change in the Comoe River Basin (West Africa). Springer Plus, 5(1), 847. https://doi.org/10.1186/s40064-0162491-z

Ziervogel, G., Nyong, A., Osman, B., Conde, C., Cortes, S., \& Dowing, T. (2006). Climate variability and change: Implications for household food security (Assessments of Impacts and Adaptations to Climate Change (AIACC) Working Paper No. 20). The AIACC Project Office, International START Secretariat, Washington DC, USA.

\section{Copyrights}

Copyright for this article is retained by the author(s), with first publication rights granted to the journal.

This is an open-access article distributed under the terms and conditions of the Creative Commons Attribution license (http://creativecommons.org/licenses/by/4.0/). 